\title{
O lugar do cancro na estatística sanitária portuguesa (1850-1933)
}

\author{
Rui Manuel Pinto Costa $\left(^{*}\right)$ \\ (*) Investigador do CITCEM-FLUP (Centro de Investigação Transdisciplinar: Cultura, Espaço, \\ Memória - Faculdade de Letras da Universidade do Porto). rcosta75@gmail.com
}

Dynamis

[0211-9536] 2011; 31 (2): 527-551
Fecha de recepción: 3 de mayo de 2010

Fecha de aceptación: 3 de mayo de 2010

SUMARIO: 1.-Uma doença rara, ou raramente diagnosticada? 2.-Higienismo e política de saúde: a origem dos défices da estatística. 3.-O tempo de despertar para um novo flagelo. 3.1.-Azevedo Neves e o Relatório de 1904. 3.2.-A intervenção política e o imperativo da luta contra o cancro. 4.-O IPO na evolução da precisão estatística: o real lugar do cancro. 5.-Considerações finais.

RESUMO: O objectivo deste artigo é mostrar a influência dos estudos estatísticos no processo de estabelecimento da luta contra o cancro em Portugal. Numa toada francamente higienista e num quadro de progressiva consciencialização sobre a doença, o lugar do cancro tornouse cada vez mais visível e incontornável no primeiro quartel do século XX, transformando-se no flagelo dos tempos modernos. Em larga medida, tal visibilidade fez-se à custa da análise estatística, processo que em Portugal assumiu a forma de relatórios, nem sempre completos e não raro subvalorizadores da realidade. Se o impacto destes relatórios não se fez no imediato, foram eles que a médio prazo sedimentaram o estabelecimento político-institucional do Instituto Português para o Estudo do Cancro, estruturado em 1923 em modelos internacionais. Por sua vez, os dados obtidos no Instituto permitiram corrigir as lacunas de uma estatística deficiente no tocante à real presença da doença oncológica na estatística sanitária portuguesa dos anos 30 .

PALAVRAS-CHAVE: cancro, estatística, Portugal, saúde.

KEY WORDS: cancer, statistics, Portugal, health.

\section{Uma doença rara, ou raramente diagnosticada?}

Abordar a estatística da doença oncológica em Portugal para a segunda metade do século XIX é um desafio que colide com a ausência e fiabilidade das fontes históricas disponíveis. Os estudos de matriz histórico-estatística 
também são poucos, apesar de Johannes Clemmesen ${ }^{1}$ ter legado um notável trabalho de investigação nesta matéria.

Ao contrário da multiplicidade de trabalhos já existentes para outras realidades nacionais ${ }^{2}$, os estudos de natureza historiográfica sobre o cancro feitos em Portugal são escassos. Existem apenas algumas abordagens de cariz institucional e biográfico redigidos por Silveira Botelho, voltadas para a figura tutelar do médico Francisco Gentil e do estabelecimento que fundou: o Instituto Português de Oncologia (IPO) ${ }^{3}$. As demais, dedicaram-se apenas à génese dos centros regionais do IPO no Porto e em Coimbra ${ }^{4}$, e só muito recentemente se deu início à realização de estudos mais abrangentes sobre o impacto desta doença na contemporaneidade portuguesa ${ }^{5}$.

Parte-se, pois de uma base mínima, onde as fontes relativas à estatística sanitária portuguesa para o século XIX só existem como tal a partir do último quartel de oitocentos. A primeira estatística sanitária fiável começou a ser elaborada para Lisboa a partir de 1875, e para o Porto em 1893, pelo que até aí apenas se pode fazer uso de alguns dados hospitalares esparsos ${ }^{6}$.

Sem o recurso a estudos sistemáticos de histopatologia, e numa altura em que os meios complementares de diagnóstico eram praticamente inexistentes, até meados/finais do século XIX o diagnóstico era por vezes confuso e impreciso, o que não só conferia dificuldades acrescidas ao tratamento, mas também na realização de uma estatística séria e fiável na altura do óbito. Mesmo assim, a importância das grandes causas de morte não fica por isso menos expressa nos números que é possível coligir, adjuvadas, pelo discurso médico e político.

1. Clemmsen, Johannes. Statistical studies in the aetiology of malignant neoplasms. Vol. I, Review and Results. Copenhagen: Munksgaard; 1965.

2. Olson, James S. The history of cancer. An annotated bibliography. New York: Greenwood Press; 1989.

3. Botelho, Luís, coord. Francisco Gentil (1878-1964). Edição da LPCC; 1978; Botelho, Luís, coord. O Instituto Português de Oncologia e a luta contra o cancro em Portugal: 75 anos. Mafra: Elo; 2000.

4. Pacheco, Francisco. Ao serviço do doente oncológico: 25 anos da história do Centro do Porto do Instituto Português de Oncologia de Francisco Gentil. Lisboa: LPCC; 2002; Portugal, Instituto Português de Oncologia. Um caminho com história. Instituto Português de Oncologia Francisco Gentil, Centro Regional de Coimbra. Lisboa: IPO - Coimbra: CRO; 2003.

5. Costa, Rui. Luta contra o cancro e oncologia em Portugal. Estruturação e normalização de uma área científica (1839-1974). Tese de doutoramento. Universidade do Porto: 2010 (Inédita).

6. Boletim Mensal da Estatística Sanitária. Porto: Serviço Municipal de Saúde e Hygiene, 1893 a 1901. 
Em meados de oitocentos, o cancro continuava a ser uma doença aparentemente rara e associada à idade avançada, de tal modo que os dados colhidos para os internados no Hospital de São José em 1851/1852 mostram uma total ausência de casos presentes nas enfermarias. As enfermidades com maior número de óbitos eram as respiratórias, seguidas das cardiopatias e das diarreias. Na lista das doenças com maior prevalência estavam a sífilis, a pleuro-pulmonite e a gastro-entero-colite ${ }^{7}$.

Quando muito, existe uma ou outra referência esporádica a uma doente com scirro da glândula mamária, considerada nesse tempo a primeira fase do desenvolvimento de um tumor canceroso, mas apesar disso os diagnósticos apontados na estatística do maior hospital de Lisboa dessa altura não mostram qualquer referência à doença oncológica. $\mathrm{O}$ mesmo sucede na Estatistica pathologica das enfermidades dos hospitaes da Universidade de Coimbra no primeiro trimestre de $1859^{8}$. A singularidade da doença também pode ser depreendida da estatística do termalismo, terapia então muito em voga: das afecções dos 1200 utentes dos «Banhos do Luso» em 1858 , apenas dois figuram como doentes com cancro, ou seja, cerca de $0,1 \%$ dos banhistas ${ }^{9}$. Tendo em atenção estes dados, parece que à primeira vista a frequência do cancro em Portugal terá aumentado de modo significativo, sobretudo desde a segunda metade de oitocentos.

Mas corresponderá esta sensação à verdade? Estes dados parecem não estar em consonância com os referentes a outras realidades europeias. Em 1836 as estatísticas parisienses reproduzidas no periódico médico American Medical Intelligencer ${ }^{10}$, davam conta de números elevados de mulheres cancerosas na capital gaulesa. Seria Portugal um país tão diferente das demais realidades europeias na frequência da doença oncológica?

Afinal, qual é o lugar do cancro em Portugal no último quartel de oitocentos? Com efeito, os médicos ainda o viam como uma doença pouco comum, mas a percepção dos clínicos revela uma preocupação crescente face ao aparente aumento de casos relatados.

\footnotetext{
7. Gazeta Médica de Lisboa; 1853: 14

8. Estatistica pathologica das enfermidades dos hospitaes da Universidade de Coimbra, desde o $1^{\circ}$ até ao 31 de Março de 1859. O Instituto, Jornal Scientífico e Literario. 1860; 8: 46.

9. Estatistica Medica dos Banhos do Luso em 1858. O Instituto, Jornal Scientífico e Literario. 1860; 8: 81-82.

10. Statistics of Sexual diseases and cancer in females. The American Medical Intelligencer. 1837; I (18): 343.
} 
Uma recolha sistemática das grandes cirurgias ${ }^{11}$ entretanto efectuadas no Hospital de São José para o ano de 1859 proporciona-nos dados bastante diferentes daquilo que poderíamos aduzir se partíssemos exclusivamente da estatística hospitalar coeva. O cancro da mama e dos lábios era não só frequente, como frequentes eram também as operações realizadas para os extirpar, garantindo ainda mais a intervenção dos cirurgiões. Na primeira metade desse ano, vários foram os casos descritos, recolhidos a partir de alguns periódicos médicos, como eram a Gazeta Médica de Lisboa e o Escholiaste Médico, e posteriormente condensados na secção médica do semanário Archivo Universal.

Para além da referência esporádica à amputação de uma coxa por tumor cutâneo, a extracção de tumores mamários encabeçavam os diagnósticos das poucas cirurgias programadas ${ }^{12}$, seguidas de perto pelos cancros do lábio ${ }^{13}$, e por fim, da língua ${ }^{14}$. Estes dois últimos tipos foram assunto que pela sua crescente incidência fez reflectir os médicos, numa altura em que ainda não se efectuava nem registo nem análise de qualquer estatística cirúrgica ao respeito:

«Já se tem notado que as affecções cirúrgicas, até as menos sugeitas á influencia de constituições medicas, tem a sua epocha de predilecção para apparecerem nos hospitaes. Ha pouco foi a epocha dos calculos vesicaes, agora é a dos cancroides do lábio inferior. Como em nenhum dos jornaes medicos publicados em Lisboa se tem notado regularmente as operações que se fazem no grande hospital de S. José, esperamos que no fim d um certo tempo a nossa revista poderá offerecer a este respeito uma estatistica curiosa» ${ }^{15}$.

Apesar da existência de dados demográficos relativamente fiáveis desde $1875^{16}$, a verdade é que a estatística sanitária entretanto publicada se encontra enviesada pela ausência ou escassez de dados específicos sobre a

11. As grandes cirurgias de meados do século XIX eram aquelas que correspondiam à necessidade de cloroformizar o doente.

12. Archivo Universal. 1859; 4: 58; 14: 219; 16: 251; 18: 284; 22: 363; 23: 395.

13. Archivo Universal, 1859; 2: 28; 7: 108; 9: 139; 21: 332.

14. Archivo Universal. 1859; 10: 156

15. Archivo Universal. 1859; 9: 139.

16. Annuario Estatistico de Portugal (1875 a 1900). Lisboa: Imprensa Nacional; 1877-1907; Censo da População do Reino de Portugal no 10 de Dezembro de 1890. 3 vols. Lisboa: Imprensa Nacional; 1896-1900 e Censo da População do Reino de Portugal no $1^{\circ}$ de Dezembro de 1900. 3 vols. Lisboa: Imprensa Nacional; 1905-1906. 
doença oncológica, bem como pelo número elevadíssimo de óbitos registados com causa indeterminada, com o que se vêm cerceadas desde logo as hipóteses de realizar um estudo preciso sobre a mortalidade por cancro. Sobre a prevalência, ainda menos se poderia aventar para este período.

Existem dados fraccionados para Lisboa, Porto e Coimbra entre 1883 e 1886, publicados por Maximiano Lemos ${ }^{17}$, e que coincidem com as estatísticas oficiais, mas não são a melhor fonte por se reduzirem a uns meros três anos de registo de óbitos.

Os défices de registo eram já bem conhecidos daqueles que tentavam fazer uso da nova metodologia estatística, mas que se deparavam com uma confrangedora falta de informação devidamente compilada e trabalhada. Aquando dos encontros internacionais sobre estatística mortuária, Portugal apresentava falhas significativas que faziam reflectir os médicos ${ }^{18}$. Com esta peia vêem-se cerceadas desde logo as hipóteses de realizar um estudo preciso sobre a mortalidade por cancro. Sobre a prevalência, ainda menos se poderia aventar para este período.

Existem dados sobre os movimentos de admissões e altas dos hospitais, mas não sobre os diagnósticos realizados. Contudo, é possível obter uma imagem razoável da presença da doença oncológica em Lisboa para o período de 1886 a 1892, através da Estatística mortuária e metereológica de Lisboa, publicada semanalmente no periódico médico A Medicina Contemporânea, bem como do Boletim Estatístico Demográfico e Médico publicado pelo Pelouro da higiene da cidade de Lisboa e inserto em O Correio Médico de Lisboa, para o período entre 1881 e 1885. A comparação entre os números fornecidos pelas duas fontes para períodos de tempo iguais, isto é, para anos iguais, mostra que os dados insertos em A Medicina Contemporânea são mais completos que os do Correio Médico, pelo que usámos os desta última publicação para os anos de 1881 a 1885 , e daí em diante os de $A$ Medicina Contemporânea.

Da compilação e distribuição desses dados por ano, podemos obter uma ideia muito aproximada do lugar da doença oncológica no seio da mortalidade olisiponense (veja-se o gráfico 1 ).

17. Lemos, Maximiano. Annuario dos progressos da medicina em Portugal. 3 vols. Porto: 1884-1886, relativo aos anos de 1883 a 1885.

18. Veja-se Martins, José. Considerações em torno da deficiente estatística mortuária do nosso país, a propósito de um pedido feito sobre o assunto pelo Congresso de Estatística realizado em Bruxelas. Jornal da Sociedade de Ciências Médicas de Lisboa. 1877: 4. 
Gráfico 1. Mortalidade geral na cidade de Lisboa (1881-1892)

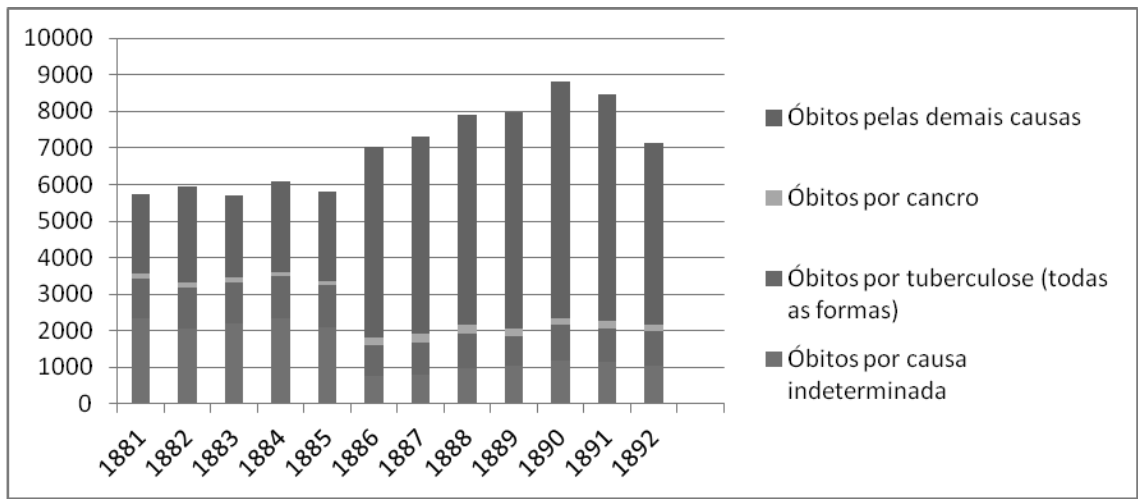

Fonte: 1881 e 1885: dados recolhidos a partir do Boletim Estatístico Demográfico e Médico publicado pelo Pelouro da hygiene da cidade de Lisboa e inserto em O Correio Médico de Lisboa (1881-1885). 1886 a 1892: dados insertos em A Medicina Contemporânea. (Ia Série) Ano X (1892), por serem mais completos, diferindo quantitativamente em relação aos do Boletim Demográfico.

Nota: não existem dados para a 38 semana de 1888 , e ainda para a 13a $14^{a}$, $22^{a}$ e $38^{a}$ semana de 1892.

A mortalidade geral corresponde aos 44 tipos que existem nos dados recolhidos: febre intermitente e renitente, gripe, varíola, sarampo, escarlatina, difteria, garrotilho, tosse convulsa, febre tifóide, tifo exantemático, disenteria, afecções puerperais epidémicas, erisipela, piémia e septicemia, gangrena nosocomial, tétano, tuberculose pulmonar, outras tuberculoses, cólera, catarro intestinal agudo, reumatismo agudo, endocardite e pericardite, lesões orgânicas do coração, apoplexia cerebral, bronquite aguda, pneumonia aguda, pleurisia aguda, nefrite aguda, debilidade congénita, vícios de conformação e monstruosidades, hidrocefalia, escrofulose, raquitismo, cancro, atrépsia, escorbuto, púrpura hemorrágica, gota, litíase renal e vesical, diabetes, alcoolismo, acidentes, suicídios, homicídios e outras doenças. Não inclui os nados-mortos.

O gráfico 1, apesar de estar propositadamente elaborado para comparar visualmente o cancro com a tuberculose (primeira causa de morte na altura), mostra igualmente a fraca fiabilidade das estatísticas apresentadas, pelo volume muito significativo de óbitos por causa indeterminada, o que revela o pouco cuidado colocado na elaboração de milhares de certidões de óbito. Muitos nem sequer chegavam a ser classificados, daí que o proverbial desdém português por uma estatística rigorosa faz supor que o número de 
mortes pelo cancro fosse superior. Por outro lado, muitas delas figuravam certamente no obituário com diferente rubrica.

Acresce outro facto não menosprezável: a designação das causas de morte podia não merecer confiança quando as certidões eram passadas pelo regedor, de acordo com o disposto no artigo 249 da lei do registo civil, que permitia aos regedores a verificação dos óbitos, quando fosse de todo impossível ser feita pelo médico, o que no meio rural acontecia com alguma regularidade ${ }^{19}$.

As principais causas de morte para este período são desde logo a tuberculose pulmonar e outras tuberculoses, seguida de longe pelas lesões orgânicas do coração, os acidentes vasculares cerebrais (apoplexia cerebral), bronquites e pneumonias, a varíola e o cancro, este último com valores superiores ao que uma abordagem empírica poderia fazer supor. Apesar dos números apresentados serem significativos, não permitem senão algumas generalizações sobre o peso da doença oncológica nas causas de morte; mas para todos os efeitos a frequência dos óbitos por cancro seria claramente superior à suposta.

À imagem de Lisboa, cujo distrito contribuía com o maior número de doentes com cancro para as cartas estatísticas, esta doença começava a destacar-se em todo o território, o que ficaria mais tarde provado pelo primeiro estudo estatístico oncológico realizado em Portugal em 1904, pela mão de Azevedo Neves. A comissão que secretariou, apresentou três relatórios que o próprio resumiu numa nota publicada em A Medicina Contemporânea em 1906. Os resultados assustavam: dos casos obtidos na observação clínica, 90\% morreram no mesmo ano.

Os picos de mortalidade causadas pelas diferentes crises epidémicas ao longo de todo o século XIX e sobretudo na sua $2^{\text {a }}$ metade, deixavam de ter um alcance nacional e tornaram-se mais circunscritas a determinadas regiões, perdendo também nos grandes efectivos humanos que habitualmente lhes sucumbiam. Com efeito, desaparece a mortalidade catastrófica a partir de meados de oitocentos ${ }^{20}$, ao passo que outra tomará progressivamente o seu lugar: despontando entre os antigos flagelos, o cancro começava a destacar-se.

19. Carqueja, Bento. O Povo Portuguez. Aspectos sociaes e económicos. Porto: Livraria Chardron; 1916, p. 308-309.

20. David, Henrique. Alguns aspectos da mortalidade em finais do século XIX - as cidades do Porto e Lisboa. Revista da Faculdade de Letras. 1992; 9: 269-294. 


\section{Higienismo e política de saúde: a origem dos défices da estatística}

Entre 1850 e 1910, os poucos hospitais que não recaíam na esfera privada das Misericórdias eram apenas os Hospitais Civis de Lisboa, o Hospital Joaquim Urbano, no Porto, os Hospitais Escolares de Lisboa e Coimbra, e ainda os hospitais militares. Não existia nenhum estabelecimento hospitalar público ou privado que se dedicasse de forma exclusiva ao tratamento dos doentes oncológicos.

O contexto sócio-sanitário em que se começa a desenhar a luta anticancerosa foi o do preventório e do higienismo. $\mathrm{Na} 2^{\text {a }}$ metade do século XIX as preocupações higienistas passaram a assumir uma dimensão progressivamente mais relevante na política de saúde portuguesa ${ }^{21}$. Acentuou-se desde a entrada em vigor da reforma sanitária de Ricardo Jorge em 1901, assente numa política devedora dos princípios da medicina preventiva, decorrente do movimento sanitário que percorrera a Europa no século XIX, e que chegava por fim à letra da lei em Portugal.

A legislação fundamental que orientava os serviços de saúde pública era o Regulamento Geral dos Serviços de Saúde e Beneficência Pública de 24 de Dezembro de 1901, mas a experiência veio demonstrar que a Direcção Geral de Saúde não podia acompanhar, vigiar, orientar e fiscalizar os serviços de 273 subdelegações de saúde, tantos quantos os concelhos onde funcionavam. Por outro lado, os subdelegados de saúde relegaram para segundo plano a acção sanitária, limitando a sua actividade ao preenchimento dos mapas estatísticos que, com esse fim, lhes eram remetidos pela Direcção Geral.

Se por um lado a legislação sanitária vigente desde o início do século XX alargou pelo país uma rede de funcionários especialmente encarregada do estudo estatístico e demográfico das doenças, exceptuando os dos três centros científicos de Lisboa, Porto e Coimbra, a organização desse estudo apenas excepcionalmente se organizava, e quando se coordenava, não era fácil o seu exame a quem não desempenhava funções sanitárias oficiais.

Em 1916, Bento Carqueja não deixou de apontar as dificuldades que encontrou na compilação de uma bioestatística fidedigna, num país onde reconhecia a escassez de

21. Cosme, João. As preocupações higio-sanitárias em Portugal (2.a metade do século XIX e princípio do XX). Revista da Faculdade de Letras do Porto. História. 2006; 7: 181-195. 
«dados para se apreciar devidamente o grau de saúde e robustez da sua população. Faltam ainda muitos elementos demográficos a que podia recorrer-se para julgar do vigor da raça, da resistência vital, das aptidões da capacidade physica, do trabalho do povo portuguez e que só podem ser colhidos mediante inquéritos feitos pelo governo, ou entidades particulares, ajudadas por elle» ${ }^{22}$.

O problema da fiabilidade prosseguiu, pelo menos até meados dos anos trinta. Ao apresentar os seus dados estatísticos para o período 1916-1925, o higienista Francisco Correia chama a atenção para

«uma dificuldade que se encontra em Portugal a juntar-se à enorme percentagem de $1 / 3$ de óbitos de causa ignorada, qual é a preguiça ou descuido, que ainda seria compreensivel em funcionários mal pagos como são os delegados de saúde, mas que se verifica na maior parte da classe médica, principalmente na de larga e bem remunerada clientela» ${ }^{23}$.

Da totalidade de óbitos registados entre 1916 e 1925 é de assinalar a média de 1.777,8 óbitos anuais devidos à doença oncológica. Olhando para este número apenas em termos absolutos, o cancro não constituía, pois, um problema de saúde pública que pudesse afectar no imediato o panorama sanitário nacional. Mas na esmiuçada resenha apresentada pelo mesmo higienista, é-nos ainda possível verificar a imprecisão deste número, provavelmente muito superior na realidade, quando verificamos cifras elevadíssimas de causas indeterminadas e ainda várias doenças não especificadas.

O problema estava na escassez de funcionários adstritos ao aparelho higio-sanitário. Em 1936, Almerindo Lessa deixava transparecer o investimento limitado que o poder político ainda realizava nesta matéria, em clara deriva com o articulado legal:

«O Estado tem em organização a sua utensilhagem servida já por um pessoal quasi-mínimo que soma no Continente 334 delegados de saúde, 692 médicos municipais, 78 médicos escolares, 90 fiscais do trabalho e 200 enfermeiras visitadoras (...) O pessoal é pouco, bastante inferior mesmo aos

22. Carqueja, n. 19, p. 245.

23. Correia, Fernando. Portugal sanitário. Subsídios para o seu estudo. Dissertação para Doutoramento em Medicina na Universidade de Coimbra. Coimbra: 1937; p. 193. 
mínimos admitidos em Higiene rural (1 médico por 1.500 a 2.000 pessoas e 1 enfermeira visitadora por 6.000 a 8.000 habitantes.» ${ }^{24}$.

Disto resultava a maior dificuldade sempre que era necessário determinar a disseminação de qualquer doença e em apurar os factos que se relacionavam com a sua etiologia.

O cancro não fugia a esta realidade. Imbuído do rótulo de doença social de dimensões colectivas, desde os primeiros anos do século XX que foi reunido sob a cobertura semântica que albergava um conjunto mais alargado, constituído também pelo alcoolismo, lepra, tuberculose e doenças venéreas.

Seria o «quarto flagelo da humanidade» ${ }^{25}$, como referia Sousa Júnior em 1911, emparelhando cada vez mais com a tuberculose, a sífilis e o alcoolismo na lista dos flagelos da espécie humana, não sem a agravante de estar em crescendo, enquanto os demais decaíam. Mesmo assim, o combate à sífilis e ao alcoolismo eram vistos como sinérgicos da luta a empreender contra o cancro, retardando ainda mais um investimento público no combate específico da doença oncológica ${ }^{26}$. Conquanto os dados oficiais ainda o contradissessem, as estatísticas incompletas e sujeitas a erros grosseiros, davam azos a afirmações que apontavam para um peso muito superior do cancro na mortalidade, de tal modo que se estaria a morrer mais de cancro do que de sífilis e de tuberculose.

Uma dessas provas é o movimento cirúrgico hospitalar de finais do século XIX, de onde é possível extrair um conjunto de exemplos que expressam o peso do bisturi no tratamento do cancro. Reflectem também uma realidade cirúrgica em franco processo de afirmação, visível nos registos de doentes oncológicos internados nas enfermarias adstritas à Escola Médico-Cirúrgica do Porto e no hospital da Universidade de Coimbra em 1883 e $1885^{27}$. Data de 1889 a primeira cura depois da extirpação de um tumor sólido do ovário, e a primeira histerectomia abdominal por mioma uterino. Dois anos mais tarde teria lugar a primeira ressecção total de um recto canceroso por via sagrada (processo de Kraske), mas a que sobreveio a morte do doente ${ }^{28}$.

\footnotetext{
24. Lessa, Almerindo. Livro de Higiene. Lisboa: Nunes de Carvalho Editor; 1936, p. 35.

25. Diário do Senado. 1911; 13: 8.

26. Lima, José. O problema do cancro: etiologia e tratamento. Porto: Escola Médico-Cirúrgica do Porto; 1907, p. 455

27. Lemos, n. 17.

28. Resenha das operações praticadas na Casa de Saúde Lisbonense, de 1886 a 1891. A Medicina Contemporânea. 1892; 10 (3): 20-21.
} 
Das 56 cirurgias realizadas na Casa de Saúde Lisbonense entre 1886 e 1891, nada menos que 25 se deveram a doença oncológica e/ou suas recidivas, sobretudo cancro da mama, do recto e da língua. Das 39 realizadas em 1891 na enfermaria masculina dirigida por Gregório Fernandes no Hospital Real de S. José, 9 deveram-se a tumores da língua ou da cavidade oral, e dos órgãos genitais masculinos. ${ }^{29}$

Os números apontados são significativos, e repetem-se um pouco por todos os hospitais do país, sobretudo naqueles que apresentam os dados relativos à actividade cirúrgica, mais precisamente os de Lisboa, Coimbra e Porto. No cômputo geral das cirurgias realizadas, ressalta claramente uma frequência relativamente elevada da doença oncológica, expressão sangrante de uma dolorosa realidade tendencialmente emergente no panorama sanitário português.

Uma análise do movimento operatório do Hospital Geral de Santo António do Porto para o ano de 1904, permite detectar rapidamente a real expressão do cancro no trabalho médico. Predominavam sobretudo os tumores da mama e do aparelho genital feminino, provando a existência de um problema emergente e muito comum na praxis cirúrgica da época. Em 762 actos cirúrgicos, 77 tinham subjacente um qualquer tipo de cancro. Estes quase $10 \%(\approx 9,89 \%)$ de intervenções, transmitem um volume considerável de casos oncológicos (veja-se o gráfico 2).

\section{O tempo de despertar para um novo flagelo}

Num país com taxas elevadas de doenças como a tuberculose, varíola, febre tifóide, tifo exantemático, sífilis e malária, o problema do cancro poderia de algum modo ser visto como menor quando colocado em mera comparação. Vistas pelos higienistas portugueses como «verdadeiros índices de falta de civilização ou de conveniente assistência» ${ }^{30}$, as doenças acima referidas constituíam o fulcro das preocupações biopolíticas do Estado; e se o problema do cancro se destacasse, sê-lo-ia apenas por força de um discurso médico, capaz de determinar a intervenção do poder político no combate

29. Estatísticas hospitalares. Hospital Nacional e Real de S. José. Enfermaria de S. Francisco (homens), sob a direcção do sr. Gregório Rodrigues Fernandes. Mappa das operações praticadas nos dois semestres de 1891. A Medicina Contemporânea. 1892; 10 (16): 116-117.

30. Correia, n. 23, p. 290. 
Gráfico 2. Cirurgias a doenças oncológicas no Hospital Geral de Santo António - Porto (1904)

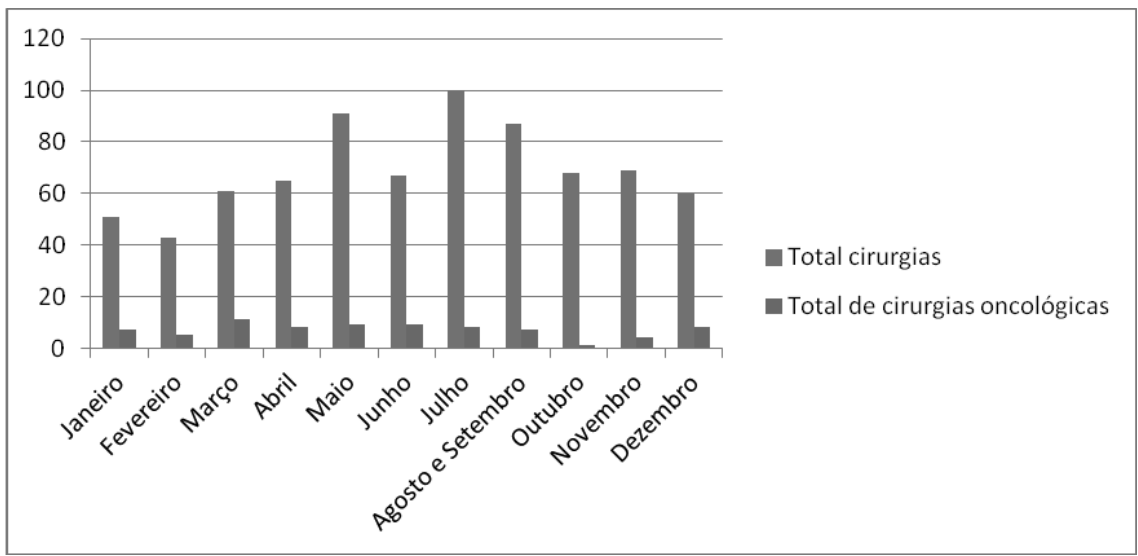

Fonte: Obtido a partir da Estatistica Operatória do Hospital Geral de Santo António (1904), publicada mensalmente no Porto Médico (Abril de 1904 a Abril de 1905).

a uma doença tão específica, que por si só era capaz de por em causa os conceitos e métodos higienistas assumidos pela política sanitária vigente.

Por antigo que fosse o seu conhecimento, a doença oncológica não partilhava as características das doenças contagiosas: não se manifestava como uma epidemia, não aparecia directamente ligada a nenhum ilícito moral ou de comportamento, incidindo sobretudo sobre a população adulta mais idosa, se bem que se sabia que podia sobrevir em qualquer idade e/ ou condição social.

Parece claro que está ausente das preocupações sanitárias dominantes, bem longe do peso que as epidemias tradicionalmente ocupavam no imaginário social de novecentos ${ }^{31}$. Contudo, a partir de meados do século XIX, a apreensão relativa à sua aparente progressão foi reforçada por um conjunto de novos dados estatísticos que faziam pensar que a taxa de mortalidade pela doença estava a aumentar nas nações ditas civilizadas. Restava saber se este aumento seria a tradução viva de uma realidade patológica em expansão, ou devido apenas a um diagnóstico mais preciso.

31. Silva, Júlio. O imaginário social das epidemias em Portugal no Século XIX. Lusíada. 2004; 2 (1): 95-125. 
A publicação dos primeiros periódicos médicos dedicados ao cancro começa a realizar-se numa base regular desde finais do século XIX, contribuindo para lançar estas e outras dúvidas, mas também para voltar o olhar de médicos e cientistas sobre a doença. A influência destas revistas no tecido clínico português seria determinante para a galvanização de um pequeno conjunto de médicos, particularmente daqueles ligados às áreas da cirurgia, anatomia patológica e investigação. Uma delas seria a Révue des Maladies Cancéreuses, publicação francesa que desde 1895 se tornou presença habitual nos estabelecimentos de ensino médico e nos principais hospitais do país.

Levantavam-se várias vozes, sobretudo da elite médica ligada à investigação, pedindo que se tomassem medidas no sentido de controlar a progressão desta nova calamidade social. A imprensa acompanhou esta tendência ao publicar os resultados de estudos realizados no território nacional desde 1904, bem como alguns artigos especificamente voltados para esta temática.

\subsection{Azevedo Neves e o Relatório de 1904}

Por iniciativa governamental, em Janeiro de 1904 o problema começou a entrar na fase dos primeiros estudos epidemiológicos de fundo, despertando as consciências médicas e políticas, e tornando-se rapidamente no centro das atenções de um pequeno conjunto de médicos que a ele se começam a dedicar de modo mais sistemático. Seguindo o exemplo de estudos similares elaborados noutros países europeus, em particular o de uma iniciativa alemã coeva, foi criada uma comissão encarregada do estudo do cancro ${ }^{32}$, encabeçada pelo então Director-Geral de Saúde e Beneficência Pública, João Ferraz de Macedo e secretariada por João de Azevedo Neves. Ambos estiveram na Alemanha, onde tiveram oportunidade de tomar contacto com a realidade do estudo epidemiológico aí realizado.

Outros elementos desta primeira comissão incluíam Curry Cabral, Oliveira Feijão e Custódio Maria de Almeida, todos eles ligados à Escola Médico-Cirúrgica de Lisboa ou ao Hospital Real de São José. 
Mas foi Azevedo Neves, que na qualidade de secretário da comissão, coligiu os numerosos relatórios estatísticos que deram corpo ao trabalho, tendo-se tornado no principal responsável pela execução e recomendações do relatório final. Foi a partir destas recomendações que se procedeu à individualização de duas enfermarias num pavilhão do Hospital do Desterro, por Curry Cabral, dedicado ao tratamento de doentes oncológicos. Foram estes os primeiros espaços físicos conhecidos no país, que lhes eram exclusivamente reservados.

A escolha de Azevedo Neves obedeceu a um princípio de racionalidade científica, encontrando-se de algum modo relacionada com o facto de ser o director do laboratório de análise clínica do Hospital de São José, e ainda por ter tido a oportunidade de assistir em Berlim aos trabalhos iniciais do comité alemão sobre o cancro nos anos de 1901-1902, o que certamente lhe terá deixado a ideia de iniciar em Portugal um trabalho semelhante.

Começou por recolher material anátomo-patológico e reviu cerca de 98.000 boletins clínicos arquivados na secretaria do Hospital Real de São José. De seguida, procedeu ao estudo clínico e laboratorial de doentes oncológicos no departamento de análise clínica do mesmo hospital. Realizou ainda um inquérito em parceria com os demais membros da comissão, que foi remetido a todos os médicos municipais do país (Continente e Ilhas). Apesar de não se mostrar totalmente específico no que concernia à diferenciação da tipologia cancerosa, a aplicação deste questionário teve o mérito de demonstrar estatisticamente a crescente frequência deste tipo de doença em Portugal. A publicação dos resultados fez-se no seio da mais destacada imprensa médica, despertando um vivo interesse pela doença oncológica ${ }^{33}$.

Dos 1.739 médicos consultados responderam 1.307 - 75,2\% do totalproporção muito satisfatória quando comparada com a de outros países onde tiveram lugar semelhantes iniciativas, o que conferiu um grau elevado de fiabilidade e consistência aos resultados obtidos. O Comité espanhol obteve $4 \%$ de respostas, o alemão $42 \%$, o holandês $60 \%$, o sueco $95 \%$ e o húngaro 96\%. Do total de respostas se concluiu que em 1904 havia 1.188 doentes em tratamento: 447 homens e 741 mulheres

Atentando à obituária de 1904, que refere 1.320 mortes por cancro, e tendo em atenção a população do continente e ilhas que se cifrava em 
5.555.814 habitantes, chega-se a uma taxa de 23,7 óbitos por cada 100 mil habitantes. Esta taxa de mortalidade específica eleva-se progressivamente e de modo rápido, sem proporção com o acréscimo normal da população. Em 1902 a média era de 22,8 subindo em 1903 para 23,4. Uma parte destes resultados foi apresentada em 1908, sob a forma de dois quadros, no congresso da Sociedade Internacional de Cirurgia que teve lugar em Bruxelas, e um ano mais tarde publicados na imprensa médica alemã ${ }^{34}$.

O assunto estava na ordem do dia, e trazia-se à arena da discussão epidemiológica um facto de incontestável valor demográfico, como parecia ser a disseminação cancerosa em Portugal. Independentemente do modo como se destrince a estatística, o facto é que apesar das preocupações legítimas da classe médica e dos poderes públicos perante este problema emergente de saúde pública, a estatística do cancro noutros países europeus apresentava valores substancialmente mais elevados do que a portuguesa. Para o mesmo período de tempo, a Suíça tinha uma taxa de 134 por 100.000 habitantes, a Holanda 92,7 e a Inglaterra 82,9.

Apenas quando se fazia a análise para os dois principais centros urbanos de Lisboa e Porto se tinha uma real percepção da frequência nessas áreas, respectivamente 79,3 e 76,8 por 100.000 habitantes, valores que se aproximam muito mais daqueles expressos pelas demais realidades europeias. Globalmente, o sexo feminino era o mais afectado, muito à custa da elevada percentagem de cancro da mama e do útero. Mas para além destas constatações de natureza estatística, pouco mais se conseguia extrair do relatório senão uma série de dúvidas que emergiam naturalmente, em face dos resultados: porque razão apresentávamos uma das mais elevadas taxas de cancro da mama da Europa? De que modo o estilos de vida e a precocidade sexual influenciavam estes números? Num país onde ainda havia malária, seria de supor alguma influência desta na baixa incidência de cancro em áreas onde a malária era endémica? Era quase impossível formular uma conclusão bem fundamentada sobre a etiologia do cancro,

34. Neves, Azevedo. Die Portugiesische Kommission für Krebsforschung. Zeitschrift für Krebsforschung. 1909; 7: 180; Neves, Azevedo. Bericht über die Zählung der im Mai und Juni 1904 in Portugal in ärztlicher Behandlung gewesenen Krebskranken. Zeitschrift für Krebsforschung. 1909; 7: 297; e Neves, Azevedo. Untersuchung vorgenommen im Jahre 1904 in den überseeischen portuguiesischen Provinzen, um die Zahl der in ärztlichen Krebskranken festzustellen. Zeitschrift für Krebsforschung. 1910; 8: 239. 
apenas com base nos ensinamentos coligidos sobre os antecedentes dos doentes portugueses.

Apesar de todas estas dúvidas, a unanimidade quanto ao futuro do cancro parecia quase garantido: para além da frequência constatada, supunha-se igualmente que a tendência desta tipologia de doenças fosse o da progressão contínua. Constatando muito mais do que a elevada frequência de um conjunto de doenças oncológicas, o estudo denotava a necessidade de um maior investimento na investigação médica face a um problema em crescendo de importância nas causas de morte dos portugueses.

Da mesma maneira, o impacto do relatório também se fez sentir junto do público, onde o interesse sobre a doença começa igualmente a despertar, plasmado no destaque que colhe nas linhas da imprensa mais generalista, desde o diário O Século ao jornal O Popular:

«Na última reunião da commissão incumbida de estudar o desenvolvimento do cancro em Portugal e de propor as medidas a adoptar para restringir tanto quanto possível a propagação d’esta terrível enfermidade, foi pelo respectivo secretário, sr. dr. Azevedo Neves, presente uma nota dos trabalhos já realisados, que constitue um volume de 70 páginas e é o resumo d um outro muito maior, que brevemente será publicado.(...) N`elles se faz um estudo completo sobre o cancro, indicando-se o desenvolvimento que esta doença tem attingido entre nós e tudo que de melhor ha feito no estrangeiro para a combater» 35 .

Para além do estudo epidemiológico promovido pela comissão supracitada, outros surgiram no mesmo ano, chegando mesmo a antecedê-lo em alguns meses, mas relativos a realidades regionais mais circunscritas. Os resultados também não deixavam de expressar preocupação, prefigurando um problema de saúde pública a levar cada vez mais em linha de conta.

Num artigo voltado exclusivamente para a principal cidade nortenha, Sousa Júnior mostrava-se atento à estatística do cancro, publicando em Abril de 1904 os resultados relativos à cidade do Porto ${ }^{36}$. Entre 1893 e 1902, o número de óbitos causados inequivocamente por cancro foi de 963, ou seja, uma média de 59 por cada 100 mil habitantes vivos, o que correspondia em média a $1,9 \%$ de todos os óbitos em cada ano.

35. Estudo do Cancro no Nosso Paiz. O Popular, 12 de Dezembro de 1906.

36. Junior, Sousa. O cancro no Porto. Porto Médico. 1904; 1 (1): 34-41. 
Apesar de resultarem de um estudo que não era de todo completo, estes dados foram obtidos a partir dos registos de óbitos compilados em estatísticas pregressas, e não em inquéritos com respostas parcelares, pelo que a fiabilidade do mesmo se pode levar em linha de conta. Os resultados reflectem não só a mortalidade específica mas também as localizações e as diferenças por sexo, inscrevendo-se em larga medida no que o estudo da Comissão publicará mais tarde.

A análise de Sousa Júnior confere uma dimensão gráfica muito mais visível ao problema canceroso no Porto. Tendo por si só um lugar de destaque no cômputo nacional em termos de mortalidade específica, ao compararem-se estes dados do caso portuense com os obtidos com o relatório de 1904, verifica-se que a mortalidade por cancro excedia, em mais do dobro, a média nacional para a mesma doença.

Mais grave ainda era situação em Viana do Castelo, onde os óbitos se situavam nos $2,5 \%{ }^{37}$. Neste último estudo, que abarca o período de 1894 a 1903, verifica-se que a cancerisação em Viana era, pois, superior à do Porto e quase duplicava a média da obtida em Espanha ${ }^{38}$.

Atingindo sobretudo os indivíduos com mais de 20 anos, a cifra do cancro feminino rondava o dobro da masculina, tanto mais que aproximadamente $42 \%$ de todos os cancros eram exclusivos da mulher, nomeadamente o cancro da mama e o genital. Esta constatação foi posteriormente reforçada por outros estudos, como o de Luís Adão publicado em 1925, assunto novamente abordado pelo mesmo autor em $1933^{39}$.

\subsection{A intervenção política e o imperativo da luta contra o cancro}

Em termos de intervenção sanitária, a actuação do poder político ficou-se pela solicitação do relatório de 1904, e durante os anos seguintes o assunto permaneceu alheado das prioridades da saúde pública. Oficialmente, o problema parecia poder ser remetido para os laboratórios da universidade ou das escolas médico-cirúrgicas, sem que isso implicasse um empenho

\footnotetext{
37. D’Almeida, Thiago. O cancro em Vianna do Castelo. Porto Médico. 1904; 1 (5): 196-200.

38. O cancro na Espanha. Porto Médico. 1904; 1 (1): 16-18.

39. Adão, Luis. Diagnóstico e tratamento dos cancros do seio. A Medicina Contemporânea. 1933; 51 (20): 128-132.
} 
particular do Estado, que a realizar-se, seria indubitavelmente dispendioso, e como tal indesejável.

Numa das entrevistas publicadas pelo Diário de Notícias em 1921, João Marques dos Santos revelou publicamente o atraso em matéria de luta anti-cancerosa, traçando um quadro preocupante, ressalvando a inexistência de uma assistência organizada, a dispersão dos doentes por enfermarias gerais, a ausência de acção profilática, a inexistência de uma consulta externa organizada, e ainda a descoordenação dos processos ainda rudimentares de terapêutica ${ }^{40}$.

Apesar do impacto do relatório de Azevedo Neves, a oportunidade e interesse político na institucionalização da luta contra o cancro demorou vários anos a concretizar-se, não sendo senão uma ideia apontada por alguns professores de medicina, sobretudo em Lisboa e Coimbra, que só em 1923 acabariam por se ver concretizadas, com a criação e financiamento do Instituo Português para o Estudo do Cancro em 1923. Mais tarde designado por Instituto Português de Oncologia e dirigido por Francisco Gentil, foi desde logo afecto e centralizado em redor dos laboratórios da Faculdade de Medicina de Lisboa.

A criação deste estabelecimento teve no relatório estatístico de 1904 um dos pilares que justificou a sua existência legal, contribuindo posteriormente para determinar de modo mais correcto o real lugar do cancro na estatística sanitária portuguesa. Em meados dos anos vinte, o discurso de Francisco Gentil e o de Marques dos Santos, tinha já penetrado nas preocupações dos responsáveis políticos, que citavam com frequência os estudos coevos, referindo que «se pode considerar o cancro uma séria ameaça para a saúde e a existência de todas as raças» ${ }^{41}$. Numa toada ainda francamente higienista e num quadro de progressiva consciencialização sobre a doença, o lugar do cancro tornou-se cada vez mais visível e incontornável, transformando-se no flagelo dos tempos modernos.

\footnotetext{
40. Santos, João. A Luta Anti-Cancerosa em Portugal. Coimbra: Imprensa da Universidade; 1925, p. 39.

41. Frederick L. Hoffman, citado no Decreto no 9.333. Diário do Governo. 1923; 278.
} 


\section{O IPO na evolução da precisão estatística: o real lugar do cancro}

As doenças infecto-contagiosas, venéreas e parasitárias, com especial relevo para a tuberculose, a sífilis, febres tifóides, varíola, difteria, escarlatina e meningite, eram sem dúvida as mais frequentes e também as que mais matavam. Eram, no pensamento dos higienistas desse tempo como postulava Ricardo Jorge, a imagem de um atraso na educação higiénica das populações, que no geral eram fruto da pobreza, mas também da negligência e ignorância relativamente a aspectos básicos de higiene pessoal, familiar e social.

Em muitas ocasiões, o discurso médico de matriz mais higienista e preventiva fazia uma associação entre o cancro e a sífilis ou até mesmo entre o cancro, a tuberculose e a própria lepra, ${ }^{42}$ colocando no controle e prevenção destas últimas uma esperança de redução da própria doença oncológica. A sífilis, em particular, era considerada precursora de lesões pré-cancerosas, ideia muito presente no pensamento médico português, que encarava a erradicação da doença venérea como profilaxia directa do cancro. $^{43}$

Além das doenças epidémicas, com períodos de maior ou menor incidência, apesar da sua habitual recorrência, foram a tuberculose, a sífilis e o reumatismo as que maior número de doentes conduziram às instituições hospitalares $^{44}$.

Contudo, a estatística que se pode coligir sobre as principais causas de morte, e como tal, da natureza das principais enfermidades que acometiam os portugueses ao longo dos primeiros decénios de novecentos, não pode ser considerada de nenhum modo absolutamente correcta. É, na melhor das circunstâncias, genericamente exemplificativa da realidade patológica nacional. Note-se que a esmagadora maioria dos óbitos era classificada com causa ignorada ou mal definida, pelo que tais estatísticas permitem deduzir apenas conclusões genéricas.

Uma vez que nem sempre os dados fornecidos pela estatística demográfica correspondiam aos fornecidos pela clínica hospitalar, também podemos fazer uso da informação relativa aos hospitais de maior dimensão,

\footnotetext{
42. D’Almeida, José. Profilaxia do bacilo de Koch: luta contra a tuberculose, lepra e cancro. 2a ed. Lisboa: Livraria Bertrand; 1939.

43. Coelho, Sabino. Sífilis e cancro do colo do útero. A Medicina Contemporânea. 1932; L (24): 199; Gentil, Francisco. Cancro e sífilis. Boletim do Instituto Português de Oncologia. 1934; 1(9).

44. Correia, n. 23, pp. 158-159.
} 
mais precisamente do São José em Lisboa, e do Santo António no Porto, para o que existe informação, respectivamente, para 1913 e 1914 (veja-se o quadro 1).

Quadro 1. Permilagem da mortalidade global hospitalar por diversas doenças no Hospital de São José e de Santo António (1913-1914)

\begin{tabular}{lcc}
\hline & $\begin{array}{c}\text { Hospital de São José } \\
(1913)\end{array}$ & $\begin{array}{c}\text { Hospital de Santo António } \\
(1914)\end{array}$ \\
\hline Tuberculose & 219,03 & 249,45 \\
Lesões orgânicas do coração & 40,43 & 37,19 \\
Cancro & 41,70 & 54,70 \\
Debilidade senil & 41,28 & 15,32 \\
Pneumonia & 32,01 & 21,88 \\
Febre tifóide & 16,42 & 17,50 \\
\hline
\end{tabular}

Fonte: adaptado de Carqueja, n. 19, p. 309.

De facto, o cancro não era doença de declaração obrigatória, sendo muitas vezes confundido com outras enfermidades. É ainda de estranhar a ausência total de referências a óbitos por quaisquer doenças venéreas, que podem estar ou não, no cômputo das causas mal definidas ou das não especificadas. Por outro lado, esta ausência pode igualmente ter a ver com o facto de muitos sifilíticos morrerem de complicações directamente resultantes da doença, em particular as de natureza cardíaca, que recaíam no cômputo das lesões orgânicas do coração.

Em muitos casos feita por médicos em franca proximidade com as famílias dos falecidos, a certidão de óbito podia facilmente conter um registo de causa desconhecida ou indeterminada, o que acrescentava uma grande dificuldade na realização de uma estatística epidemiologicamente correcta ou sequer aceitável.

Com efeito, quando a partir dos anos trinta a percentagem de óbitos de causa ignorada baixa brutalmente, dos 38,6\% (1916-1925) para 8,8\% (1930-1933), é apenas a partir daí que passamos a ter uma imagem muito mais completa, fiável, mas ainda mais preocupante sobre o problema do cancro. Neste aspecto, a informação conferida pela estatística hospitalar e demográfica é inegável e clarificadora.

O facto do Instituto Português do Oncologia se encontrar em funcionamento desde 1923, contribuiu decisivamente para a recolha de dados 
suficientes, essenciais à realização de um necessário reajuste estatístico, claramente mais consentâneo com a realidade da doença oncológica em Portugal, tanto mais que a esmagadora maioria dos dados sobre esses óbitos eram provenientes desse estabelecimento hospitalar (veja-se o gráfico 3).

Gráfico 3. Número de mortes anuais por cancro em Portugal (1902-1930)

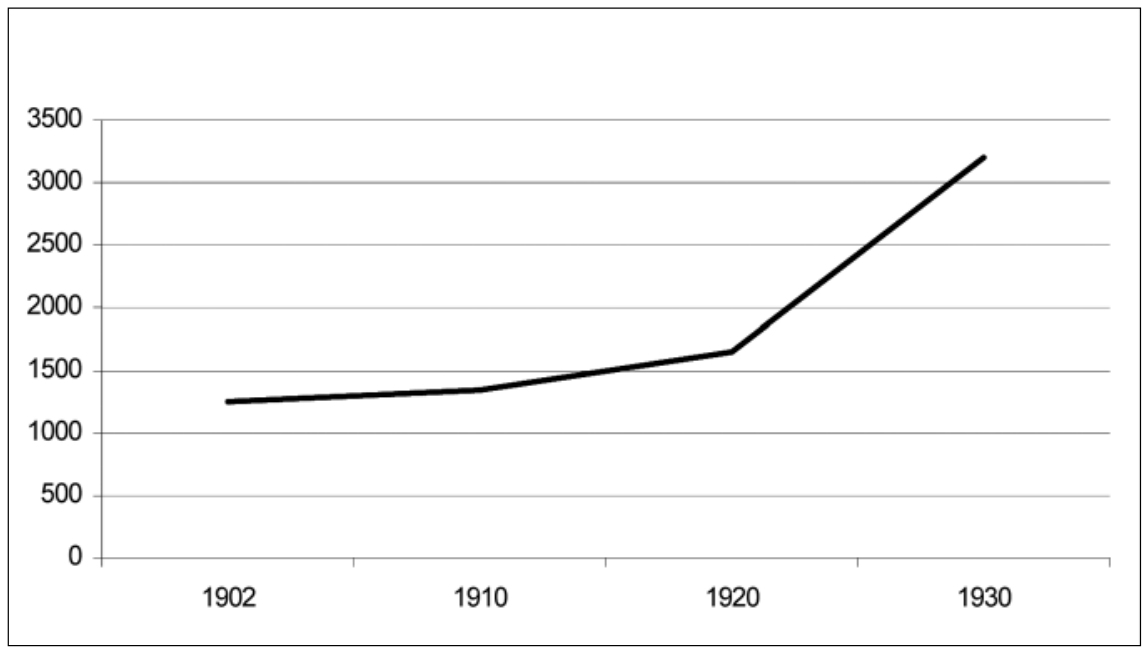

Fonte: adaptado de Correia, n. 23, p. 572.

Foi então possível conferir credibilidade à sensação manifestada por muitos médicos acerca da prevalência do cancro na sua prática clínica diária, desde o dealbar do século XX, altura em que o contacto com ela assumia foros de uma certa rotinidade:

«Se aos médicos que vivem a mourejar pela clinica das cidades e das aldeias lhes fosse possivel, que nem sempre o é, registar todos os casos da sua observação, com a publicação das observações e reunião dos dados que pudessem recolher, constituir-se-ia a história pormenorisada n’um ramo importante da patologia nacional» ${ }^{45}$. 
Foi por iniciativa do IPO, em colaboração com o Instituto Nacional de Estatística e a Direcção Geral de Saúde, que se deu início a uma estatística organizada e tão rigorosa quanto possível sobre a mortalidade e morbilidade pelo cancro em Portugal. Dotado de um serviço próprio afecto exclusivamente à estatística, o IPO desenvolveu nos seus primórdios uma das principais bases em que incidiria a sua actividade inicial. Organizado por Florentino da Costa Ramos, que entretanto estagiara no Instituto Gustave Roussy de Paris, tornou-se um instrumento indispensável para a avaliação e aferição dos caminhos a empreender na luta contra o cancro ${ }^{46}$. Sem ela, não seria possível traçar um plano de experiências laboratoriais, orientar e definir as condições de um inquérito, formular os resultados das observações clínicas; enfim, apreciar com segurança a validade das conclusões.

Apesar de ser ainda incompleta, por não incluir todos os mortos do país por doença oncológica, a estatística do IPO conferiu uma maior segurança aos resultados entretanto obtidos. Nos primeiros seis anos do seu funcionamento, os números oficiais mostraram um quadro bastante mais claro (veja-se quadro 2).

Quadro 2. Relação entre doentes oncológicos e não oncológicos observados no IPO (1928-1933)

\begin{tabular}{cccccc}
\hline & \multicolumn{2}{c}{ Doentes inscritos } & \multicolumn{2}{c}{ Doentes com cancro } & Percentagem \\
\cline { 2 - 5 } Ano & Homens & Mulheres & Homens & Mulheres & doentes com cancro \\
\hline 1928 & 250 & 702 & 176 & 451 & $65,8 \%$ \\
1929 & 424 & 1.098 & 312 & 714 & $67,3 \%$ \\
1930 & 553 & 1.439 & 353 & 848 & $60,2 \%$ \\
1931 & 592 & 1.634 & 368 & 907 & $57,2 \%$ \\
1932 & 631 & 1.771 & 351 & 1.001 & $56,4 \%$ \\
1933 & 491 & 1.224 & 340 & 990 & $78,2 \%$ \\
\hline
\end{tabular}

Fonte: Athias, M. Organisation de la Lutte contre le Cancer au Portugal. Arquivo de Patologia. 1934; 6: 551.

Do exposto se depreendia que: 
1. O número de pessoas que recorriam ao Instituto era predominantemente feminino e com tendência a aumentar. Este facto devia-se sobretudo à grande quantidade de lesões genitais femininas suspeitas.

2. Eram as mulheres que contribuíam com a maior parte dos casos de tumores malignos.

3. O facto de haver uma diminuição na percentagem de doentes oncológicos entre todos os atendidos, significava que a propaganda anti-cancerosa começava a obter alguns resultados. Com efeito, cada vez mais pessoas se faziam observar no IPO por suspeita de doença oncológica.

4. Em 1933, o número de doentes oncológicos foi o mais elevado, o que pode indiciar uma melhoria na canalização dos doentes aos serviços especializados do IPO, por parte dos clínicos gerais.

Verificou-se nessa altura que a percentagem de falecidos face aos tratados era elevadíssima, com valores absolutos que ultrapassavam largamente os demais óbitos imputáveis às doenças dominantes, como eram os casos da sífilis e da tuberculose (vejam-se os quadros 3, 4 e 5).

Quadro 3. Doentes oncológicos tratados no IPO (1930-1933)

\begin{tabular}{lrrrr}
\hline & 1930 & 1931 & 1932 & 1933 \\
\hline Doentes oncológicos tratados no IPO & 1208 & 1275 & 1354 & 1328 \\
Falecidos & 141 & 144 & 200 & 147 \\
\% de óbitos por doentes tratados & 11,6 & 11,3 & 14,7 & 11,1 \\
\hline
\end{tabular}

Fonte: adaptado de Correia, n. 23, p. 159.

Quadro 4. Doentes com sífilis tratados nos hospitais civis e militares (1930-1933)

\begin{tabular}{lrrrr}
\hline & 1930 & 1931 & 1932 & 1933 \\
\hline Sifilíticos tratados nos hospitais civis e militares & 4732 & 4545 & 4596 & 4284 \\
Falecidos & 131 & 139 & 121 & 96 \\
$\%$ de óbitos por doentes tratados & 2,7 & 3,0 & 2,6 & 2,2 \\
\hline
\end{tabular}

Fonte: adaptado de Correia, n. 23, p. 159. 
Quadro 5. Doentes com tuberculose internados e inscritos em sanatórios e dispensários da Assistência Nacional aos Tuberculosos (1930-1933)

\begin{tabular}{lrrrr}
\hline & 1930 & 1931 & 1932 & 1933 \\
\hline Internados em sanatórios da Assistência Nacional & & & & \\
aos Tuberculosos (ANT) & 1446 & 1557 & 1972 & 2030 \\
Falecidos & 21 & 57 & 91 & 113 \\
\% de óbitos por doentes tratados & 1,4 & 3,6 & 4,6 & 5,5 \\
Internados noutros sanatórios & 1048 & 1039 & 1083 & 1217 \\
Falecidos & 22 & 16 & 21 & 38 \\
$\%$ de óbitos por doentes tratados & 2,1 & 1,5 & 1,9 & 3,1 \\
\hline
\end{tabular}

Fonte: adaptado de Correia, n. 23, p. 159. (Note-se que o número total de tuberculosos inscritos em dispensários era elevadíssimo, muito superior ao dos inscritos nos da ANT)

E mesmo que a mortalidade pelo cancro em Portugal fosse das mais baixas quando comparada com outros países europeus, facto já conhecido e referido por Azevedo Neves desde 1906, o número de óbitos específico aumentava de ano para ano, o que podia ser tão só o reflexo da diminuição progressiva do número de óbitos de causa ignorada, mas também o real incremento da incidência de uma enfermidade em clara ascensão no mundo ocidental.

\section{Considerações finais}

O diagnóstico do cancro assumiu progressivamente um lugar de destaque na vida clínica de praticamente toda a classe médica desde finais do século XIX. Era um evento mórbido, que mesmo sem comprovação estatística estava presente na prática do médico da província ao facultativo, do clínico ao professor universitário.

As fissuras existentes entre uma bioestatística pouco precisa e a prática médica, mostravam bem a necessidade de diminuir as assimetrias entre a real frequência da doença e a incipiente investigação realizada em matéria oncológica.

As dificuldades colocadas pela dispersão de dados e a inexistência de uma estatística rigorosamente colhida, são os principais óbices a que se consigam aduzir conclusões sobre o verdadeiro lugar do cancro na segunda metade do século XIX. Se os dados entretanto produzidos por uma estatística mais rigorosa a partir dos anos 30 mostram frequências e óbitos 
superiores aos primeiros relatórios de Azevedo Neves em 1906, fica-se com a impressão que a frequência da doença oncológica durante a segunda metade de oitocentos seria substancialmente superior à proporcionada pelos dados publicados nas revistas médicas.

Numa toada francamente higienista e num quadro de progressiva consciencialização sobre a doença, o lugar do cancro tornou-se cada vez mais visível e incontornável no primeiro quartel do século XX. Em larga medida, tal visibilidade fez-se à custa da análise estatística, processo que em Portugal assumiu a forma de relatórios, nem sempre completos e não raro subvalorizadores da realidade.

Os primeiros dados fidedignos sobre o número de doentes tratados em instituições especializadas só surgiram na década de trinta, e se os dados obtidos antes da criação do IPO permitiram prever um futuro incremento da doença, acompanhado por uma prevalência aparentemente crescente, a estatística obtida a partir da concentração dos casos clínicos nesse estabelecimento permitiu desenhar o verdadeiro lugar do cancro, ou pelo menos conferir fidedignidade ao rótulo de flagelo eminente e perigo real à saúde pública. 